\title{
Is Severe Pulmonary Hypertension a Contraindication for Orthotopic Heart Transplantation? Not Any More
}

\author{
J. KETTNER ${ }^{1}$, Z. DORAZILOVÁ ${ }^{1}$, I. NETUKA ${ }^{2}$, J. MALÝ ${ }^{2}$, H. AL-HITI ${ }^{1}$, \\ V. MELENOVSKÝ ${ }^{1}$, I. SKALSKÝ ${ }^{2}$, H. ŘÍHA ${ }^{3}$, I. MÁLEK ${ }^{1}$, J. KAUTZNER ${ }^{1}$, J. PIRK ${ }^{2}$ \\ ${ }^{1}$ Department of Cardiology, Institute for Clinical and Experimental Medicine - IKEM, Prague, \\ Czech Republic, ${ }^{2}$ Department of Cardiovascular Surgery, Institute for Clinical and Experimental \\ Medicine - IKEM, Prague, Czech Republic, ${ }^{3}$ Department of Anaesthesiology and Resuscitation, \\ Institute for Clinical and Experimental Medicine - IKEM, Prague, Czech Republic
}

Received February 2, 2011

Accepted May 3, 2011

On-line August 1, 2011

\section{Summary}

Pulmonary hypertension $(\mathrm{PH})$ unresponsive to pharmacological intervention is considered a contraindication for orthotopic heart transplantation (OHTX) due to risk of postoperative right-heart failure. In this prospective study, we describe our experience with a treatment strategy of improving severe $\mathrm{PH}$ in heart transplant candidates by means of ventricular assist device (VAD) implantation and subsequent OHTX. In 11 heart transplantation candidates with severe $\mathrm{PH}$ unresponsive to pharmacological intervention we implanted $\mathrm{VAD}$ with the aim of achieving $\mathrm{PH}$ to values acceptable for OHTX. In all patients we observed significant drop in pulmonary pressures, PVR and TPG $(p<0.001$ for all) 3 months after VAD implantation to values sufficient to allow OHTX. Seven patients underwent transplantation (mean duration of support 216 days) while none of patients suffered right-side heart failure in postoperative period. Two patients died after transplantation and five patients are living in very good condition with a mean duration of 286 days after OHTX. In our opinion, severe $\mathrm{PH}$ is not a contraindication for orthotopic heart transplantation any more.

\section{Key words}

Pulmonary hypertension - Hemodynamics - Heart transplant candidacy $\bullet$ Ventricular assist devices

\section{Corresponding author}

Jiri Kettner, Department of Cardiology, Institute for Clinical and Experimental Medicine - IKEM, Videnska 1958/9, 14021

Prague 4, Czech Republic. E-mail: jiri.kettner@ikem.cz

\section{Introduction}

Pulmonary hypertension $(\mathrm{PH})$ occurs in up to $70 \%$ of patients with moderate-to-advanced heart failure (Butler et al. 1999). The presence of elevated pulmonary vascular resistance (PVR) or increased transpulmonary gradient (TPG) in heart failure patients who are candidates for orthotopic heart transplantation (OHTX) represents a major risk factor for post transplant right ventricular failure and is predictive of adverse outcomes after transplantation (Chen et al. 1997, Tenderich et al. 1998). Murali and colleagues documented in patients with a TPG greater than $15 \mathrm{mmHg}$ an short-term transplant mortality rate ( 0 to 2 days) 3 times higher than in patients with TPG $<15 \mathrm{mmHg}$ (Murali et al. 1993). Severe $\mathrm{PH}$ - that is, a pulmonary artery systolic pressure greater than $50 \mathrm{mmHg}$, PVR greater than 3-4 WU and TPG greater than $15 \mathrm{mmHg}$, measured after pharmacological testing - should be considered a contraindication of OHTX (Ross et al. 2003). Experiences with ventricular assist devices (VAD) showed a continuous reduction of PVR during mechanical circulatory support in patients with terminal heart failure. Some case reports and small studies demonstrated a significant decrease of PVR and pulmonary artery pressures during VAD support in candidates with severe $\mathrm{PH}$ to acceptable values for indication of OHTX (Al Khaldi et al. 2004, Martin et al. 2004, Salzberg et al. 2005). Learning from this experience, in 2007 we changed our strategy for heart 


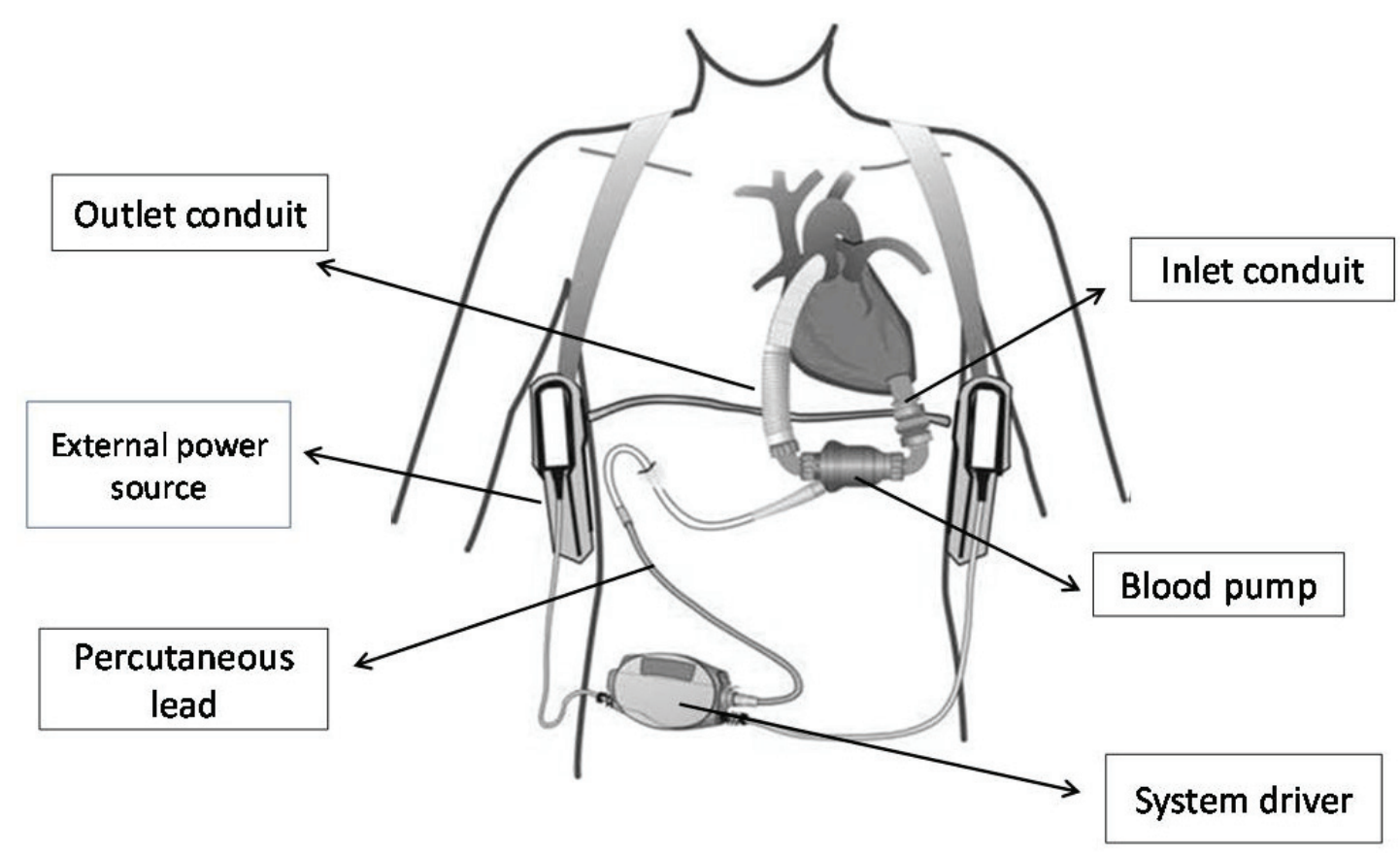

Fig 1. Heart Mate II - left ventricular assist device (LVAD), an axial-flow rotary ventricular assist device composed of a blood pump, percutaneous lead, external power source, and system driver. It is attached between the apex of the left ventricle and the ascending aorta.

transplant candidates with severe pulmonary hypertension. If a pharmacological test fails to lower PVR to less than 2.5 WU and TPG less than $15 \mathrm{mmHg}$, the patients are treated with an implantable VAD as a bridge to heart transplantation. The purpose of our prospective study was (1) to evaluate whether VAD support leads to a significant decrease or normalization pulmonary artery pressures, TPG and PVR in all patients with severe PH secondary to chronic heart failure and (2) to assess the effect of this approach on survival after OHTX in patients with pre-existing severe PH, refractory to medical therapy.

\section{Materials and Methods}

\section{Patient population}

Between January 2007 and October 2010, 62 patients at our clinic underwent implantation of VAD as bridge to heart transplantation $[14$ patients biventricular VAD (BVAD); 48 patients - left VAD (LVAD)]. Eleven (18\%) of these patients with terminal heart failure had severe $\mathrm{PH}$ unresponsive to pharmacological interventions and were contraindicated to OHTX. All these patients were chosen for implantation of VAD because of an indication of pharmacological refractory $\mathrm{PH}$ as a bridge to candidacy. The study was approved by the institutional review board, and written informed consent was obtained from all subjects before VAD implantation and subsequent heart transplantation.

\section{Devices}

The first three patients were indicated for implantation of BVAD - Thoratec PVAD (Thoratec Corp., Pleasanton, CA, USA) and the next 8 patients were treated with an implantable LVAD Heart Mate II (Thoratec Corp., Pleasanton, CA, USA; Fig. 1). The technical details and implantation procedures of these devices have been described previously (Kettner et al. 2005, Griffith et al. 2001, Netuka et al. 2008).

Measurement and testing reversibility of pulmonary hypertension

Right-sided heart catheterization was performed via right internal jugular vein with $7 \mathrm{~F}$ balloon-tipped pulmonary artery (PA) catheter (Corodyn, Braun AG, Germany). The catheter position was optimized under fluoroscopic guidance. All patients were normoxemic (oxygen saturation $>90 \%$ by pulse oxymetry) at room air temperature. Cardiac output was measured by thermodilution and at least three random measurements were averaged. The PVR was calculated as mean transpulmonary pressure gradient/cardiac output. Patients with a PVR of more than $3 \mathrm{WU}$ and/or a TPG of more than $15 \mathrm{mmHg}$ at baseline received a continuous infusion 
of PGE1 in increasing doses (alprostadil-Alprostan, Leciva, Czech Republic,) into the central vein according to our standard protocol (Kakac et al. 1996). In the case of persisting $\mathrm{PH}$ with the values for contraindication of OHTX, we indicated these patients for implantation of VAD. Three months after VAD implantation, we performed in all patients control right-sided heart catheterization, control transthoracic echocardiography and blood sampling for measurement of B-type natriuretic peptide (BNP) by CMIA (Architect BNP, Abbott, Abbott Park, Illinois).

\section{Statistical analysis}

The study was analyzed with the Statistical Package for the Social Sciences (SPSS Inc, Chicago, Illinois, USA). Data are presented as mean \pm SD. Paired variables were analysed by paired Student's t-test and BNP were compared using the Wilcoxon signed-rank test.

Table 1. Patients characteristics of the entire cohort $(n=11)$.

\begin{tabular}{|c|c|}
\hline Age (years) & $\begin{array}{c}48.9 \pm 11 \\
\text { (range } 29-59)\end{array}$ \\
\hline Gender & $\begin{array}{l}8 \mathrm{M} / 3 \mathrm{~F} \\
(73 \% \mathrm{M})\end{array}$ \\
\hline$B M I\left(\mathrm{~kg} / \mathrm{m}^{2}\right)$ & $\begin{array}{c}24.2 \pm 4.6 \\
\text { (range } 19.4-32.6)\end{array}$ \\
\hline NYHA class & III+/IV \\
\hline Indications for OHTX & $\begin{array}{ll}\text { Cardiomyopathy ischemic } & 7 \\
\text { Cardiomyopathy dilated } & 3 \\
\text { Congenital heart disease } & 1\end{array}$ \\
\hline $\begin{array}{l}\text { History of heart failure } \\
\text { (years) }\end{array}$ & $\begin{array}{c}8.82 \pm 4 \\
\text { (range } 2-14)\end{array}$ \\
\hline $\begin{array}{l}\text { BNP values before VAD } \\
\text { implantation (median; } n g / l)\end{array}$ & 2146 \\
\hline $\begin{array}{l}\text { Drugs before VAD } \\
\text { implantation (\%) }\end{array}$ & $\begin{array}{c}\text { Diuretics (100) } \\
\text { Beta-blockers (82) } \\
\text { ACE-inhibitor (73) } \\
\text { Inotropics (36) }\end{array}$ \\
\hline $\begin{array}{l}\text { CRT/ICD before } \\
\text { implantation (\%) }\end{array}$ & 64 \\
\hline
\end{tabular}

BNP: B-type natriuretic peptide; BMI: body mass index; CRT: cardiac resynchronization therapy; ICD: implantable cardioverter defibrillator; OHTX: orthotopic heart transplantation; VAD: ventricular assist device

\section{Results}

The baseline characteristics of these study patients are shown in Table 1. The mean overall age was 48.9 years ( $73 \%$ were male) and mean overall body mass index was $24.2 \mathrm{~kg} / \mathrm{m}^{2}$. All patients received maximum standard heart failure therapy. In $36 \%$ of the patients we used small doses of dopamine or dobutamine and did not need mechanical support. The most common cause of heart failure was ischemic cardiomyopathy present in 7 patients (64\%), idiopathic cardiomyopathy was present in 3 patients $(27 \%)$. All patients had a long history of end-stage heart failure (mean 8.82 years) and $\mathrm{PH}$ not responsive to pharmacological intervention with PVR 6.1 $\pm 1.4 \mathrm{WU}$, pulmonary artery systolic pressure (PAsyst) $79.8 \pm 10.7 \mathrm{mmHg}$, pulmonary artery mean pressure (PAmean) 50.7 $\pm 6.5 \mathrm{mmHg}$ and TPG 21.0 $\pm 5.2 \mathrm{mmHg}$. Detailed hemodynamic data are shown in Table 2. VAD implantation was successful in all 11 patients without complications. None of the patients required mechanical right-sided heart support after LVAD implantation. During the entire VAD support period, these patients were removed from the heart transplantation list. Overall mechanical support time was $215 \pm 131$ days (mean \pm SD; range 119-542 days). All patients with implantable LVAD Heart Mate II were discharged from hospital after 20-60 days with standard heart failure therapy. They were trained in the routine care and handling of the assist system. Hemodynamic parameters from right-sided heart catheterization before VAD implantation, after pharmacological testing and 3 months after VAD implantation are summarized in the Table 2. In all patients we observed: a significant drop in of pulmonary pressures (PAsyst before VAD $79.8 \pm 10.7 \mathrm{mmHg}$ vs. after VAD $36.2 \pm 7.7 \mathrm{mmHg}$; $<<0.001$; PAmean before VAD $50.7 \pm 6.5 \mathrm{mmHg}$ vs. after VAD $21.9 \pm 5.0 \mathrm{mmHg}$; $\mathrm{p}<0.001$ ), PVR (before VAD 6.1 $\pm 1.4 \mathrm{WU}$ vs. after VAD $2.59 \pm 0.72 \mathrm{WU} ; \mathrm{p}<0.001$; in six patients decreased to $\leq 2.5 \mathrm{WU}$ ) and TPG (before VAD $21 \pm 5.2 \mathrm{mmHg}$ vs. after VAD $10.5 \pm 2.3 \mathrm{mmHg} ; \mathrm{p}<0.001 ; 8$ patients decreased to $\leq 12 \mathrm{mmHg}$ ) 3 months after VAD implantation to values sufficient for heart transplantation (Fig. 2). Echocardiography data were obtained in all patients before and after VAD implantation and showed significant decrease of left ventricular end-diastolic dimension (LVEDD before VAD 75.5 $\pm 6.1 \mathrm{~mm}$ vs. after VAD $63.5 \pm 6.2 \mathrm{mmHg} ; \mathrm{p}<0.001$ ) with no significant changes of the ejection fraction of the left ventricle and right ventricular dimension (Table 3). BNP values 
Table 2. Data from right-sided heart catheterization $(n=11)$.

\begin{tabular}{lccccc}
\hline Variable & Before VAD & After VAD & p value & After testing & p value \\
\hline RA [mmHg] & $9.7 \pm 4.9$ & $7.2 \pm 4.7$ & 0.026 & - & - \\
PAsyst [mmHg] & $79.8 \pm 10.7$ & $36.2 \pm 7.7$ & $<0.001$ & $75.4 \pm 8.6$ & 0.010 \\
AAmean $[\mathrm{mmHg}]$ & $50.7 \pm 6.5$ & $21.9 \pm 5.0$ & $<0.001$ & $46.8 \pm 3.2$ & 0.012 \\
PWP [mmHg] & $29.4 \pm 6.3$ & $10.6 \pm 5.7$ & $<0.001$ & $27.3 \pm 4.6$ & 0.729 \\
TPG [mmHg] & $21 \pm 5.2$ & $10.5 \pm 2.3$ & $<0.001$ & $19.4 \pm 3.9$ & 0.081 \\
CO [l/min] & $3.53 \pm 0.64$ & $4.46 \pm 0.87$ & 0.002 & $4.55 \pm 0.79$ & 0.017 \\
$P V R[$ WU] & $6.1 \pm 1.4$ & $2.59 \pm 0.72$ & $<0.001$ & $4.26 \pm 0.97$ & 0.004 \\
\hline
\end{tabular}

CO: cardiac output; PAmean: mean pulmonary artery pressure; PAsyst: systolic pulmonary artery pressure; PVR: pulmonary vascular resistance; PWP: pulmonary capillary wedge pressure; RA: right atrium; TPG: transpulmonary gradient; VAD: ventricular assist device

Table 3. Data from echocardiographic examination $(n=11)$.

\begin{tabular}{lccc}
\hline Variable & Before VAD & After VAD & p value \\
\hline LVEDD $(\mathrm{mm})$ & $75.5 \pm 6.1$ & $65.5 \pm 6.2$ & $<0.001$ \\
$\operatorname{LVEF}(\%)$ & $19.73 \pm 4.92$ & $23.91 \pm 1.69$ & 0.020 \\
$R V / P L A X(\mathrm{~mm})$ & $29.21 \pm 4.15$ & $29.08 \pm 3.72$ & 0.63 \\
\hline
\end{tabular}

LVEDD: enddiastolic diameter of left ventricle; LVEF: ejection fraction of left ventricle; RV/PLAX: diameter of right ventricle from parasternal projection in long axis; VAD: ventricular assist device

3 months after VAD implantation significantly decreased from $2146 \mathrm{ng} / \mathrm{l}$ (median; range 382-5000) to $214 \mathrm{ng} / \mathrm{l}$ (median; range 11-880; Fig. 3). Seven patients underwent heart transplantation after a bridging period with a mean duration of 216 (range 124-542) days, 4 patients are still on waiting list of candidates for heart transplantation. Two patients died after transplantation, both due to severe bleeding and both with previously pulsatile BVAD use. None of the patients had right-side heart failure in either the perioperative or postoperative periods. Five patients are living in very good condition with a mean duration of 286 (range 87-599) days after heart transplantation. In 3 of these patients we performed right-sided heart catheterization between 11 and 21 days with a mean PVR $2.2 \pm 1.4 \mathrm{WU}$ and TPG $12 \pm 8 \mathrm{mmHg}$.

\section{Discussion}

Pulmonary hypertension in patients with chronic heart failure is mainly due to transmission of elevated left ventricular filling pressure into pulmonary circulation. In patients with an elevated PVR it is supposed that there are changes such as dysregulation of vascular smooth muscle tone and, depending on the duration of these processes, structural remodelling of the pulmonary vascular tree, but these mechanisms are incompletely understood. Whereas the dysregulation of the pulmonary vascular tone is readily reversed by the hemodynamic unloading or by vasodilators, structural remodelling is generally referred to as "fixed" and might be resolved, however, only slowly, taking anywhere from months to possibly years (Moraes et al. 2000). For these reasons, the pharmacologic testing of the reversibility of $\mathrm{PH}$ is an essential test in the evaluation and selection of candidates for heart transplantation. Patients with pharmacological resistant $\mathrm{PH}$ should be considered to be a contraindication of OHTX. The cut-off values for $\mathrm{PH}$ as the contraindication of heart transplantation at our department are a PVR of more than $3 \mathrm{WU}$ and/or a TPG of more than $15 \mathrm{mmHg}$ after testing. The cut-off values are based on our long-term experience with heart transplantation. The alternative strategy for approaching OHTX in patients with severe $\mathrm{PH}$ is to perform heterotopic heart transplantation or heart and lung transplantation, but the survival rates are significantly lower compared to the overall survival after OHTX (Christie et al. 2010). 


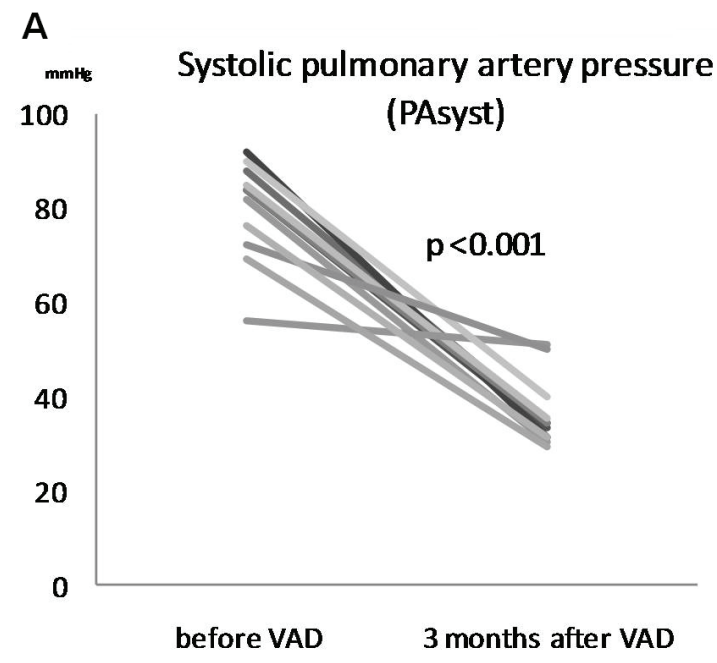

C

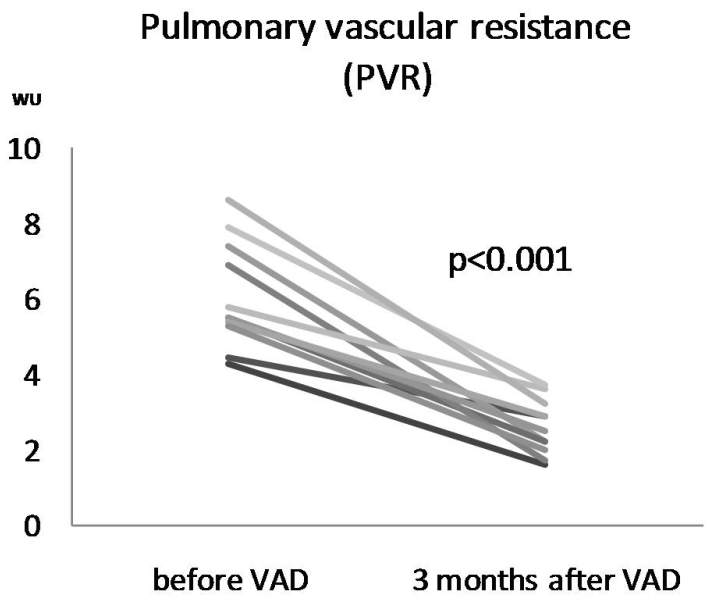

B

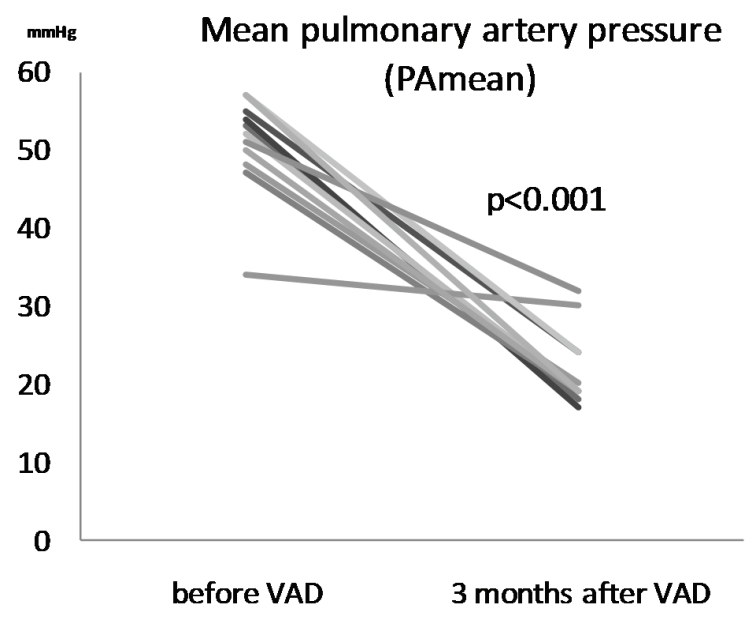

D Transpulmonary gradient

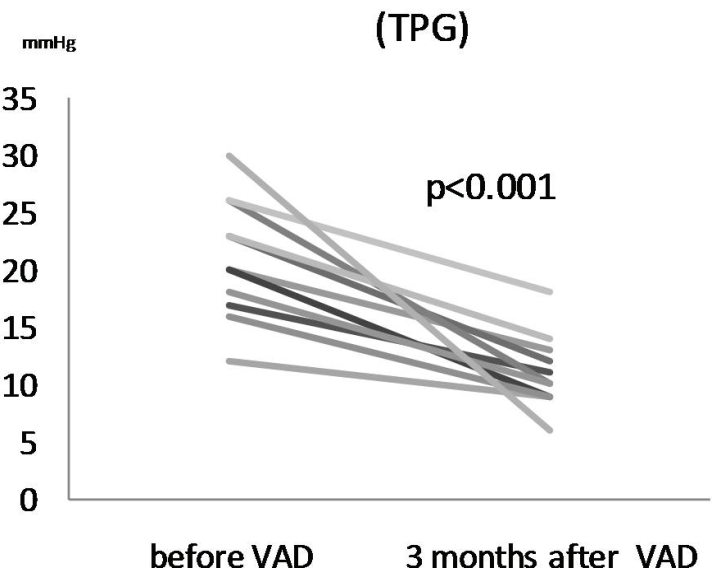

Fig. 2. Hemodynamic parameters before and 3 months after ventricular assist device (VAD) implantation in 11 patients: (A) systolic pulmonary artery pressure (PAsyst), (B) mean pulmonary artery pressure (PAmean), (C) pulmonary vascular resistance (PVR) and (D) transpulmonary gradient (TPG).

\section{BNP}

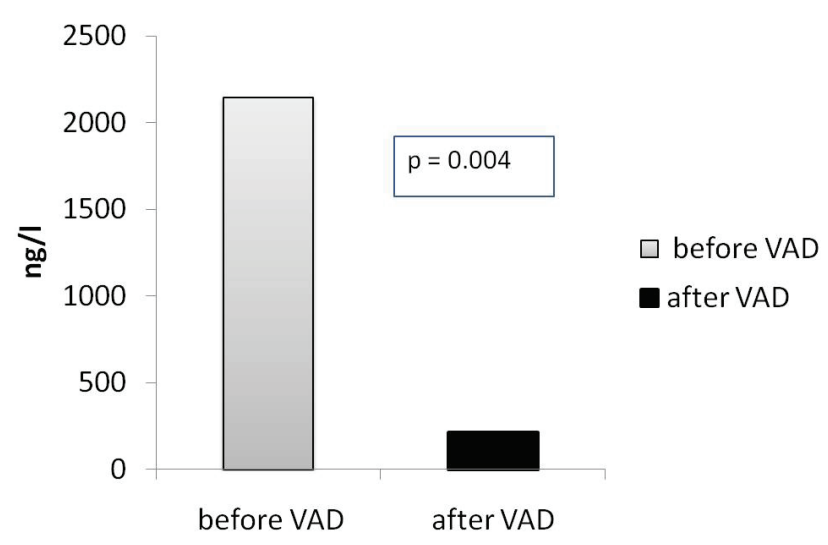

Fig. 3. B-type natriuretic peptide (BNP) levels before and 3 months after ventricular assist device (VAD) implantation in 11 patients $(p=0.004)$. BNP values are expressed as median.
With increasing our experiences with implantation of VAD as bridge to transplantation, we have observed a continuous decrease in PVR during VAD support in these patients and there is growing evidence that $\mathrm{PH}$ in chronic heart failure can be reversed after long-term mechanical support. Accordingly, we have changed our approach to these patients. With respect to the recommendation of the International Society for Heart and Lung Transplantation (Gronda et al. 2006), we began to indicate patients with pharmacologically irreversible $\mathrm{PH}$ to $\mathrm{BVAD}$ implantation. In the first 3 patients of our study, we observed that 3 months after BVAD implantation a significant drop of PVR and TPG. Zimpfer and colleagues in 2007 published very good experiences with only LVAD as bridge for heart transplantation in 35 patients with $\mathrm{PH}$ resistant to medical treatment. In all patients from this study there was a significant decrease of PVR with values acceptable for 
transplantation but more than $50 \%$ of the patients had a severe adverse event during the period of LVAD and 11 patients died in bridging period (Zimpfer et al. 2007). They used 3 different types of LVADs: the DeBakey LVAD in the majority of patients, the Novacor system, and in one patient the DuraHeart system. In our remaining 8 patients (73\%) we used the small axial flow implantable pump Heart Mate II as LVAD only. In all 8 patients, we demonstrated a significant decrease of pulmonary pressures, TPG and PVR with nearly normal values and, in contrast to Zimpfer, we observed no significant complication during the study period. In accordance with reduced intracardiac pressures we demonstrated a significant fall of BNP levels after VAD implantations. Following successful heart transplantation with no right ventricle failure and favorable early values of PVR after transplantation shows that mechanical unloading leads to lasting effects on pulmonary vascular resistance. Our results support expand the existing evidence that the major component of $\mathrm{PH}$ due to chronic heart failure is dysregulation of vascular smooth muscle tone that results in impaired nitric oxide availability and increased endothelin expression and pulmonary vasoconstriction (Moraes et al. 2000). Other additional factors include hypoxia and changes in the expression of von Willebrand factor that results in the development of platelet fibrin microthrombi (Zimpfer et al. 2007). The true structural remodelling, which irreversible fixed of $\mathrm{PH}$, is in these cases probably rare.

The major limitation of the present study is the nonrandomized design and small numbers of patients. The reason for the nonrandomized design is because severe $\mathrm{PH}$ is not responsive to pharmacological intervention as contraindication for OHTX. Therefore, comparing heart transplantation with and without prior VAD implantation would be ethically controversial.

\section{Conclusions}

Pulmonary hypertension that is secondary to congestive heart failure more than likely can be reversed to the values acceptable for OHTX by the use of pulsatile or axial-flow VADs in all cases. Because of axial-flow devices, such as the Heart Mate II, which are easier to implant (due to its smaller size and with less complications than BVAD), they are potentially suitable for this carefully selected specific candidates of heart transplantation. This strategy offers new hope and a chance of long-term survival with this approach. Accordingly, LVADs should be considered in all heart transplant candidates with $\mathrm{PH}$, which are contraindication for OHTX. In our opinion, severe PH is not at the present time a contraindication for orthotopic heart transplantation.

\section{Conflict of Interest}

There is no conflict of interest.

\section{Acknowledgements}

This work was supported by grants from Ministry of Health [MZO-00023001 and NS10497-3/2009]; Ministry of Education [MSMT-1MO510]; the Grant Agency of the Czech Republic [305/09/1390].

\section{List of Abbreviations}

BMI body mass index

BNP B-type natriuretic peptide

BVAD biventricular ventricular assist device

$\mathrm{CO} \quad$ cardiac output

CRT cardiac resynchronization therapy

ICD implantable cardioverter defibrillator

LVAD left ventricular assist device

LVEDD left ventricular enddiastolic diameter

LVEF left ventricular ejection fraction

OHTX orthotopic heart transplantation

PA pulmonary artery

PAmean mean pulmonary artery pressure

PAsyst systolic pulmonary artery pressure

PGE1 prostaglandin E1

$\mathrm{PH} \quad$ pulmonary hypertension

PVR pulmonary vascular resistance

PWP pulmonary capillary wedge pressure

TPG transpulmonary gradient

VAD ventricular assist device

WU Wood units

\section{References}

AL KHALDI A, ERGINA P, DEVARENNES B, LACHAPPELLE K, CECERE R: Left ventricular unloading in a patient with end-stage cardiomyopathy and medically unresponsive pulmonary hypertension. Artif Organs 28 : 158-160, 2004. 
BUTLER J, CHOMSKY DB, WILSON JR: Pulmonary hypertension and exercise intolerance in patients with heart failure. J Am Coll Cardiol 34: 1802-1806, 1999.

CHEN JM, LEVIN HR, MICHLER RE, PRUSMACK CJ, ROSE EA, AARONSON KD: Reevaluating the significance of pulmonary hypertension before cardiac transplantation: determination of optimal thresholds and quantification of the effect of reversibility on perioperative mortality. J Thorac Cardiovasc Surg 114: 627-634, 1997.

CHRISTIE JD, EDWARDS LB, KUCHERYAVAYA AY, AURORA P, DOBBELS F, KIRK R, RAHMEL AO, STEHLIK J, HERTZ MI: The Registry of the International Society for Heart and Lung Transplantation: Twenty-seventh official adult lung and heart-lung transplant report - 2010. J Heart Lung Transplant 29: 1104$1118,2010$.

GRIFFITH BP, KORMOS RL, BOROVETZ HS, LITWAK K, ANTAKI JF, POIRIER VL, BUTLER KC: HeartMate II left ventricular assist system: from concept to first clinical use. Ann Thorac Surg 71: S116-S120, 2001.

GRONDA E, BOURGE RC, COSTANZO MR, DENG M, MANCINI D, MARTINELLI L, TORRE-AMIONE G: Heart rhythm considerations in heart transplant candidates and considerations for ventricular assist devices: International Society for Heart and Lung Transplantation guidelines for the care of cardiac transplant candidates - 2006. J Heart Lung Transplant 25: 1043-1056, 2006.

KAKAC J, MÁLEK I, HRNCAREK M, ZELIZKO M, STANEK V: Pulmonary hypertension testing in orthotopic heart transplantation candidates using prostaglandin E1. Cor Vasa 38: 251-255, 1996.

KETTNER J, PIRK J, NETUKA I, BREZINA A, RIHA H, MALÝ J, MASIN J: Mechanical cardiac support - the first use in Czech Republic. (in Czech) Cas Lék Ces 144: 38-42, 2005.

MARTIN J, SIEGENTHALER MP, FRIESEWINKEL O, FADER T, VAN DE LOO A, TRUMMER G, BERCHTOLDHERZ M, BEYERSDORF F: Implantable left ventricular assist device for treatment of pulmonary hypertension in candidates for orthotopic heart transplantation - a preliminary study. Eur J Cardiothorac Surg 25: 971-977, 2004.

MORAES DL, COLUCCI WS, GIVERTZ MM: Secondary pulmonary hypertension in chronic heart failure: the role of the endothelium in pathophysiology and management. Circulation 102: 1718-1723, 2000.

MURALI S, KORMOS RL, URETSKY BF, SCHECHTER D, REDDY PS, DENYS BG, ARMITAGE JM, HARDESTY RL, GRIFFITH BP: Preoperative pulmonary hemodynamics and early mortality after orthotopic cardiac transplantation: the Pittsburgh experience. Am Heart J 126: 896-904, 1993.

NETUKA I., MALÝ J., SZÁRSZOI O: Ventricular assist devices in the management of terminal heart failure. (in Czech) Cor Vasa 50: 207-212, 2008.

ROSS H, HENDRY P, DIPCHAND A, GIANNETTI N, HIRSCH G, ISAAC D, SINGH N, WEST L, WHITE M: 2001 Canadian Cardiovascular Society Consensus Conference on cardiac transplantation. Can J Cardiol 19: 620-654, 2003.

SALZBERG SP, LACHAT ML, VON HARBOU K, ZUND G, TURINA MI: Normalization of high pulmonary vascular resistance with LVAD support in heart transplantation candidates. Eur J Cardiothorac Surg 27: 222225, 2005.

TENDERICH G, KOERNER MM, STUETTGEN B, HORNIK L, MIROW N, MORSHUIS M, MANNEBACH H, MINAMI K, KOERFER R: Does preexisting elevated pulmonary vascular resistance (transpulmonary gradient $>15 \mathrm{~mm} \mathrm{Hg}$ or $>5$ wood) predict early and long-term results after orthotopic heart transplantation? Transplant Proc 30: 1130-1131, 1998.

ZIMPFER D, ZRUNEK P, ROETHY W, CZERNY M, SCHIMA H, HUBER L, GRIMM M, RAJEK A, WOLNER E, WIESELTHALER G: Left ventricular assist devices decrease fixed pulmonary hypertension in cardiac transplant candidates. J Thorac Cardiovasc Surg 133: 689-695, 2007. 